\title{
Calculating of adjusted geoid undulation based on EGM08 and mean sea level for different regions in Iraq
}

\author{
Ali Fanos ${ }^{1, *}$, Rusul Tahir ${ }^{2}$, Suad Mohammed $^{1}$, and May Mahmood ${ }^{1}$ \\ ${ }^{1}$ Ministry of Water Resources, State Commission of Survey, Baghdad, Iraq \\ ${ }^{2}$ Civil Engineering Department, Al Esraa University College, Baghdad, Iraq
}

\begin{abstract}
In last decades Global Navigation Satellite System (GNSS) or as known Global Positioning System (GPS) technique is considered a revolutionary technique in the field of geodetic survey in comparison with traditional techniques (level, theodolite and total station). The height obtained from GNSS technique is ellipsoid height and to have a physical meaning in a surveying or engineering application it must be transformed to orthometric height. Therefore, a geoid model has to be used to do this transformation process. In Iraq there is no specific geoid that can be used in order to get proper orthometric height. This research aims to calculate adjusted geoid undulation based on Earth Gravitational Model 2008 (EGM08) through observation of Iraqi official vertical network using GNSS technique. Different regions in Iraq have been chosen to perform this research. The result of this research can assist a lot to enhance the accuracy of elevations obtained from GNSS and support the establishment of Iraq geoid.
\end{abstract}

\section{Introduction}

Most surveying, engineering and scientific work, orthometric heights related to the geoid, a close approximation to mean sea level (M.S.L), are needed [1]. Combining of data acquired by the global navigation satellite system (GNSS), leveling and geoid information has been a key process for different geodetic applications. Despite the fact that these three height types are significantly varies, basically in terms of physical meaning, reference surface realization/definition, accuracy and observational methods, they should fulfill the simple geometrical relationship [2]

$$
N=h-H+\varepsilon
$$

In which $h$ is ellipsoidal height derived by GNSS technique, $H$ is orthometric height obtained by spirit leveling and gravimetric, $N$ is geoid height and $\varepsilon$ is small quantity because of the curvature of the plumb line and the deflection of the vertical.

Normal height is height above the mean sea level and it is one of many height types that are all computed by slightly different methods. The others are: orthometric height and dynamic height. The normal height of a point is computed from geopotential numbers by dividing the point's geopotential number, for instance, its geopotential variance with which of sea level, by the mean, normal gravity computed along the plumbline of the point. Therefore, normal height is dependent upon the chosen of reference ellipsoid. Normal heights figure prominently in the theory of the Earth's gravity field. The reference surface which normal height is measured from is called the quasi-geoid. The representation of M.S.L similar to the geoid and close to it, but lacking the physical interpretation of an equipotential surface.

The distance $\mathrm{H}$ along a plumb line from the point to the geoid is the orthometric height of a point. Orthometric height is for practical purposes height above sea level (Fig.1).

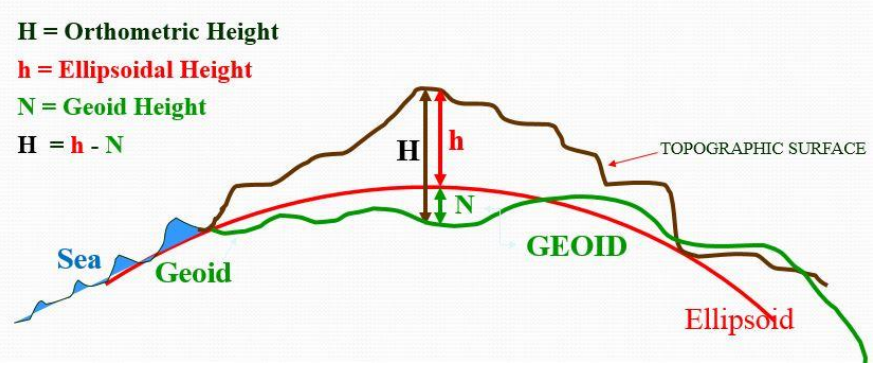

Fig.1. The difference between the orthometric and ellipsoidal height.

The geoid is the shape that the sea's surface would take under rotation and the effect of earth's gravity, in the other effects absenteeism such as winds and tides. The surface is expanded through the continents. The points on the geoid have the similar potential energy of gravity (centrifugal potential energy and the sum of gravitational potential energy). Gravity force acts everywhere perpendicular to the geoid, which means water levels parallel to the geoid and plumb lines point perpendicular [3].

Particularly, the geoid is the equipotential surface which could correspond with the mean sea surface if the atmosphere and sea were in equilibrium [4].

\footnotetext{
Ali Mutar Fanos: engalim87@gmail.com
} 
The geoid surface is lower than the reference ellipsoid wherever there is a negative gravity anomaly (mass deficit) and higher than the reference ellipsoid wherever there is a positive gravity anomaly (mass excess) [5].

Ali (2016) [6], calculated the geoidal height for different ground control points (GCPs) distributed in side Baghdad University campus based on the difference between the ellipsoidal height and the orthometric height of the same point. EGM08 has been used to calculate the maximum and the minimum values of the geoid undulation. However, the calculation of geoidal height or geoid undulation needs to be performed for wide area with well points distribution.

In last decade, GNSS technique has been widely used in Iraq. However, regarding the elevation, the local elevations in Iraq are related to the mean sea level (M.S.L) and the zero point is located in Al Faw south of Iraq. Meanwhile, there is no specific geoid that can be used in order to get proper elevation or orthometeric height. Thus, this research is trying to find the adjustment value of geoid undulation based on EGM08 through observe the local vertical network using GNSS.

\section{Geodetic referencing in Iraq}

The most significant datum in Iraq are: Karbala 1979 and The Iraq Geospatial Reference System (IGRS).

\subsection{Karbala 1979}

A completely new geodetic network was established in the 1970s by the Cartography GEOKART and Polish State Enterprise for Geodesy (Polservice) covering all of Iraq. This was a conventional astro-geodetic control network which consist of around 2780 points with an average inter-point distance of $15 \mathrm{~km}$. A new spiritleveled vertical network, tied to two tide gauges at the port of Al-Faw, supplemented the horizontal network. Observations of gravity were made along all precise leveling lines. The original point of the horizontal network was moved to Karbala instead of Nahrwan. The coordinates change of any point in Iraq is important: in the Baghdad region the shift between Karbala 1979 and Nahrwan coordinates is around 400 meters. Karbala 1979 was utilized in combination with the UTM map projections system and with a dedicated TM projection as well.

\subsection{The Iraq Geospatial Reference System (IGRS)}

USA armies after the first Gulf War establishes the beginnings of a new geodetic network, the Iraqi Geospatial Reference System (IGRS), an effort in which the Iraqi Ministry of Water Resources / State Commission on Survey played a key role. Several points of the Karbala 1979 network that still existed were observed utilizing high accuracy GNSS technique and many new points were established. A series of six Continuously Operating Reference Stations (CORS) is acting as the backbone of the IGRS, that have been utilized to extend the coverage of the IGRS primary control network.

The CORS network (Fig.2) is operated jointly by the US National Geodetic Survey, which is part of the US National Oceanographic and Atmospheric Administration (NOAA) (NGS) and the Iraq Ministry of Water Resources / State Commission on Survey. High Accuracy Reference Network (HARN) points have been established relative to the CORS network forming the IGRS control network consists.

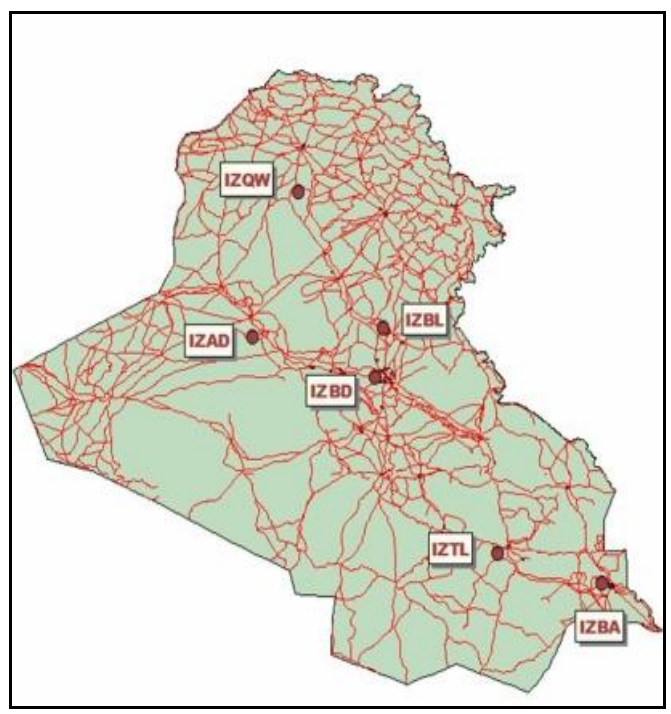

Fig.2. The distribution of initial CORS stations in Iraq.

Initially the geodetic surveying work of the IGRS network was managed by British and US Army engineers. In this phase a series of 64 HARN points have been established in southern Iraq (Fig.3). The aim of this work was to make a beginning for a nationwide HARN network with a distance of about $50 \mathrm{~km}$ between each two points.

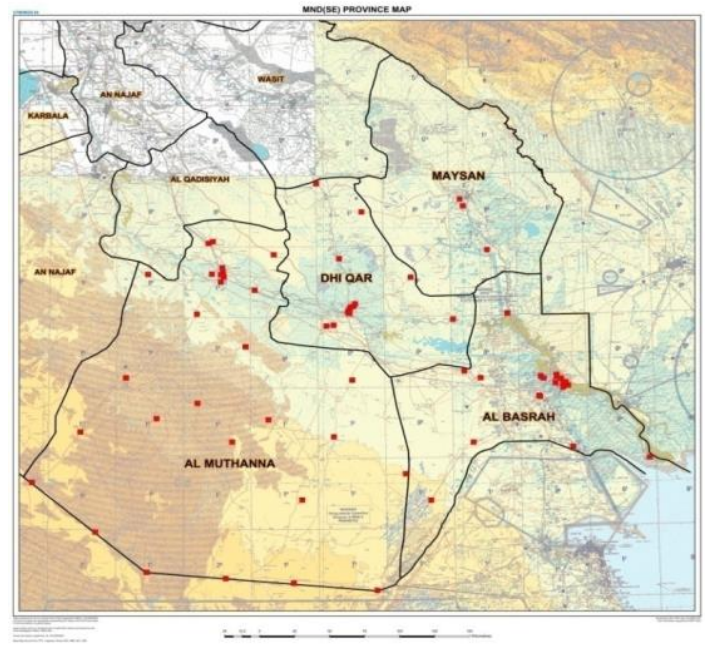

Fig. 3. The distribution of 64 HARN points in southern Iraq. 
After that Ministry of Water Resource / State Commission on Survey installed 7 CORS stations (Fig.4) and continued establishing the HARN points for whole Iraq provinces.

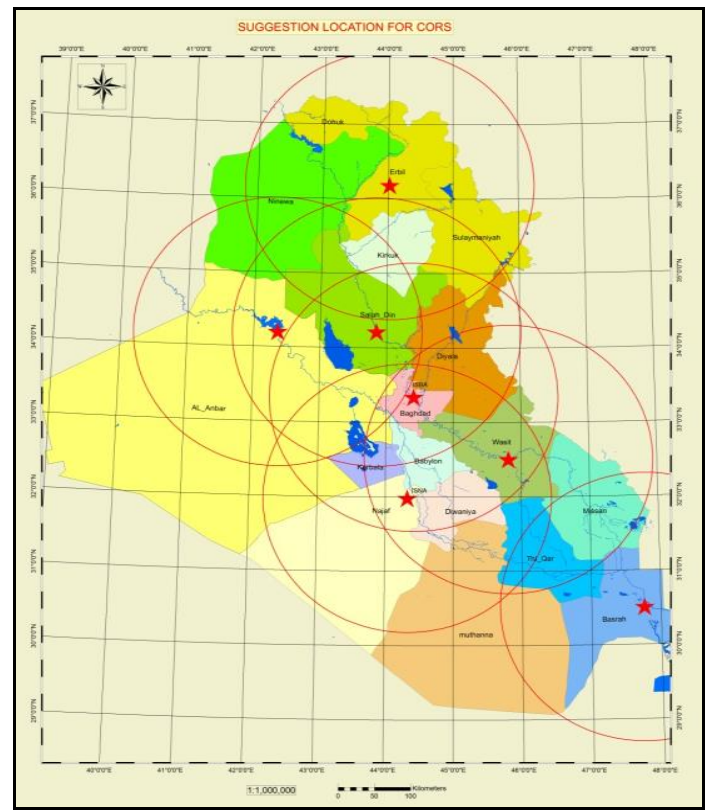

Fig. 4. The distribution of CORS stations in Iraq.

At this phase of IGRS the orthometric height of points was obtained by subtracting geoid undulation based on the EGM96 model from the ellipsoidal height that derived using GNSS technique. In that time, EGM96 model was the most accurate global geoid. Geoid undulation accuracy based on EGM96 is estimated to be not better than 0.5 meters. Therefore, orthometric height accuracy derived via EGM96 will be of the same magnitude order as the model itself ( 0.5 meter). This is much larger than the accuracy of ellipsoidal height that can be obtained through GNSS technique.

\section{Study area}

The methodology of this research has been performed in different regions in Iraq and focus on the most important provinces namely: Babylon, Karbala, Najaf, Kut, and Dioania (Fig.5). GNSS technique has been widely used in these regions due to the increase of projects that have been carrying out in these provinces in terms of oil, construction, industrial and other projects. That is why this research focus on these regions.

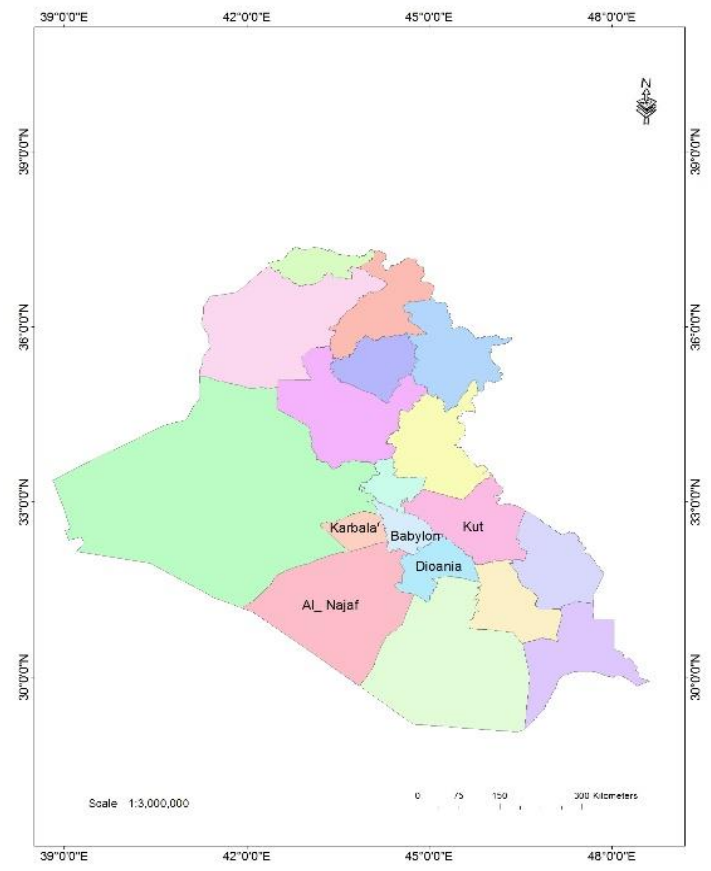

Fig. 5. The study area.

\section{Methodology and material}

The methodology of this research can be divided into two aspects the first one is the reconnaissance and observation of the local vertical network by GNSS technique, the second one is measuring of HARN points by GNSS and by precise level based on local vertical points.

\subsection{Reconnaissance and observation of the local vertical network}

The local vertical network is based on Faw mean sea level and consist of many leveling lines covering whole Iraq (Fig.6). Each line has many points and each point has a number printed on it. The number consists of two parts the first one refers to the line number and the other refers to the point number (for instance, 35 - 10 it means line number 35 and the tenth point in the line). The shape of the points are pyramid on a cube (Fig.7).

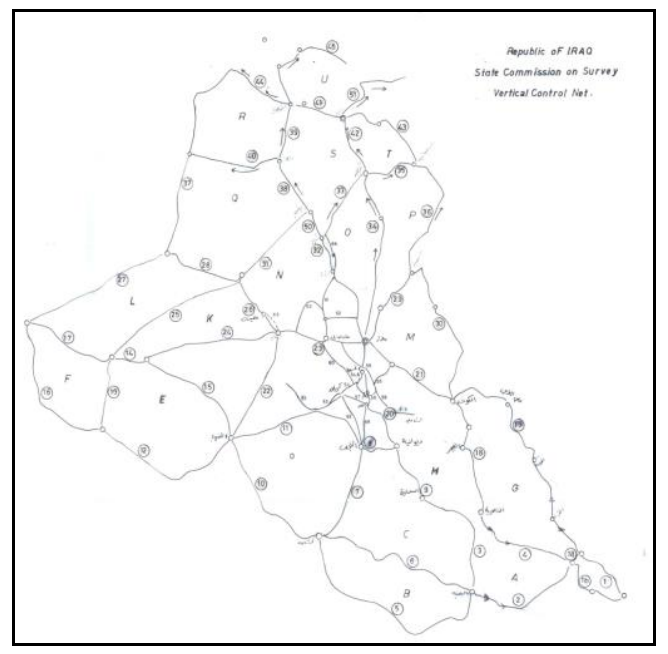


Fig. 6. Precise leveling lines.

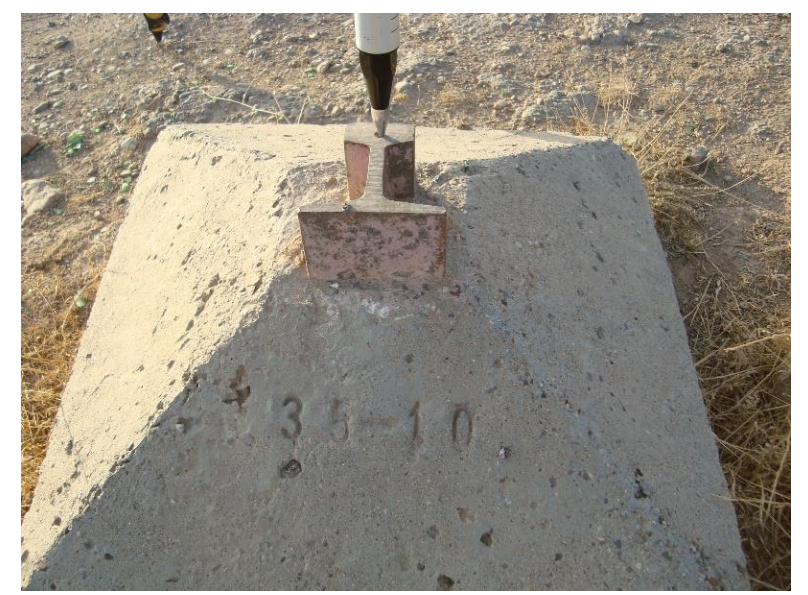

Fig.7. A precise leveling point.

Reconnaissance has been performed to the lines in concerning province based on points sketch that prepared previously by the company that established the vertical network (Polservice). This process has been carried out in order to know the existing points because some points have been damaged or removed. After that, a plan has been made to specify which points will be observed in a specific line. Then the points have been measured using GNSS technique (Topcon GR3 and Trimble 5700) (Fig.8). Each point has been observed for five hours. Then the raw data has been sent to NGS after one month from the observation date to do post-processing based on Iraq CORS station and get very accurate information in terms of longitude, latitude, and altitude in addition to $\mathrm{x}, \mathrm{y}, \mathrm{z}$. Then EGM08 has been used in order to get geodetic height or orthometric height which supposed to be same the Faw M.S.L. After that, the difference between the height obtained by GNSS and the actual height for each point has been calculated which represents the adjustment value of geoid undulation.

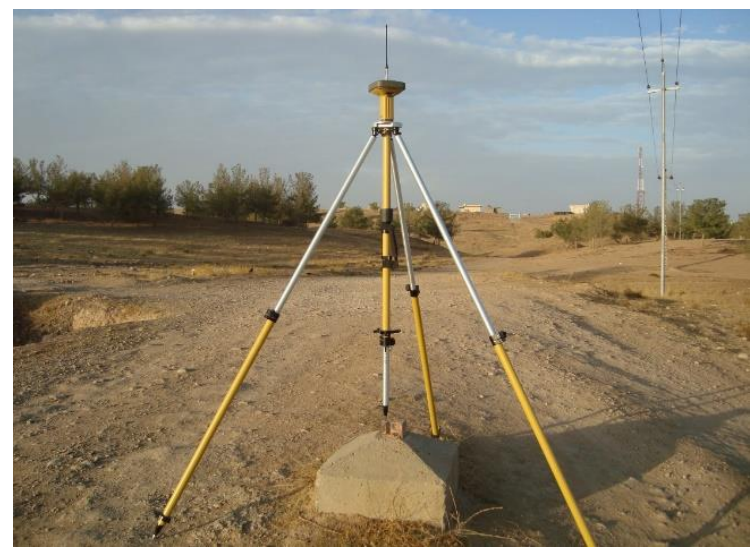

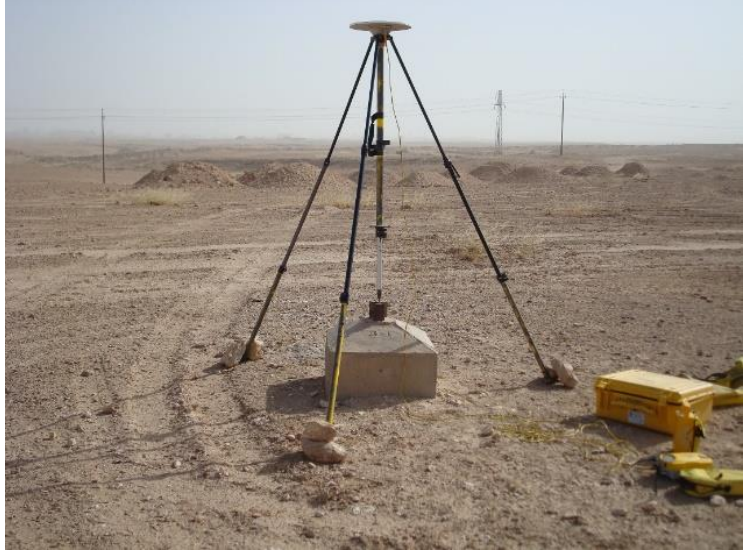

Fig. 8. Observation process for local vertical points.

\subsection{Measuring of HARN points}

State Commission on Survey has established many HARN points distributed in all Iraq (Fig.9). This process has been performed based on standard design that NGS follows (Fig.10), and also based on maximum and minimum distance between each two points.

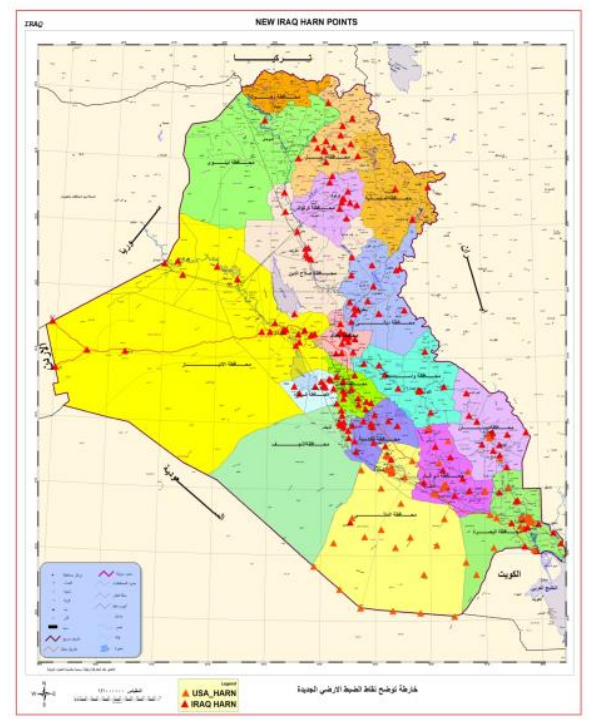

Fig. 9. The distribution of HARN points which established by S.C.S.

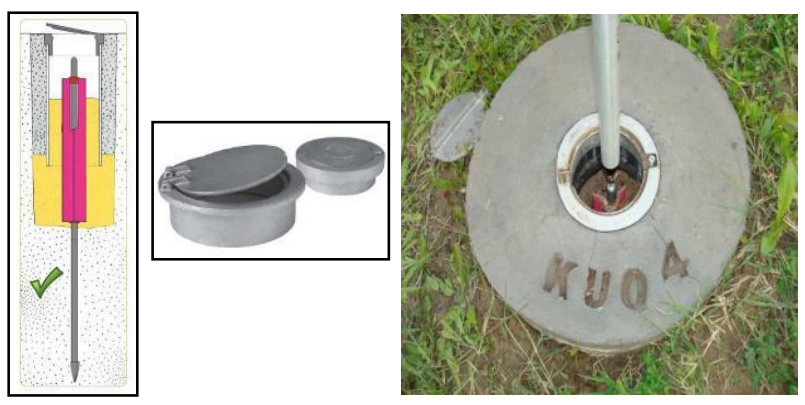

Fig. 10. Design of HARN points.

All HARN points have been observed using dual frequency GNSS receiver (Fig.11), in two sessions each 
one for 5.5 hours and the data processing has been carried out by OPUS program through NGS website.

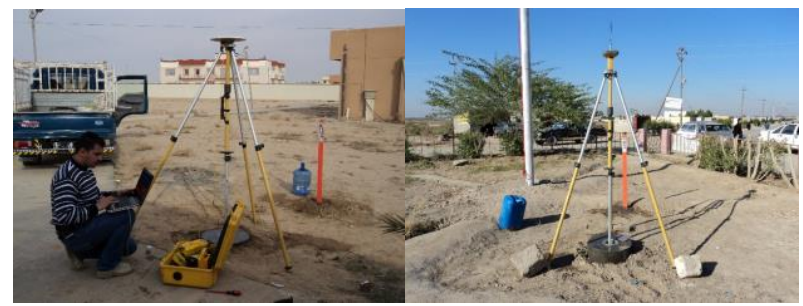

Fig. 11. Observing of HARN points.

Almost all the HARN points (Appendix 1) have been measured based on the nearest local vertical point. This process has been carried out using two precise level and two operators and do the double check to get accurate measurements. Then the difference between the orthometric height obtained by GNSS and precise level has been calculated for each HARN point and added to the geoid undulation $(\mathrm{N})$ which obtained by applying EGM08 to get adjusted $\mathrm{N}$ for each point. After that, the average of the difference has been calculated to represent the adjustment value of $\mathrm{N}$ obtained using GNSS in each province.

Root mean square error (RMSE) is a frequently used measure of the differences between values (measured or calculated value and actual value). RMSE has been applied in order to check the accuracy

$$
R M S E=\sqrt{\frac{\sum_{t=1}^{n}\left(h_{\text {Faw }}-h_{\text {EGM08 }}\right)^{2}}{n}}
$$

In which $n$ is the number of points, $h_{\text {Faw }}$ is the orthometric height based on Faw mean sea level, and $h_{E G M 08}$ is the orthometric obtained from GNSS based on EGM08.

\section{Results and discussion}

Figure (12) illustrates the difference between ellipsoidal height, orthometric height based on Faw mean sea level and orthometric height obtained by GNSS using EGM08. This figure shows the difference for the five provinces (Babylon, Karbala, Najaf, Kut and Dioania). In all provinces, the orthometric height based on Faw mean sea level and EGM08 is almost same with a small difference. The difference between orthometric height (both Faw and EGM08) and ellipsoidal height is cleared in this figure. The smallest difference between orthometric height and ellipsoidal height is in Karbala and the highest difference is in Kut.
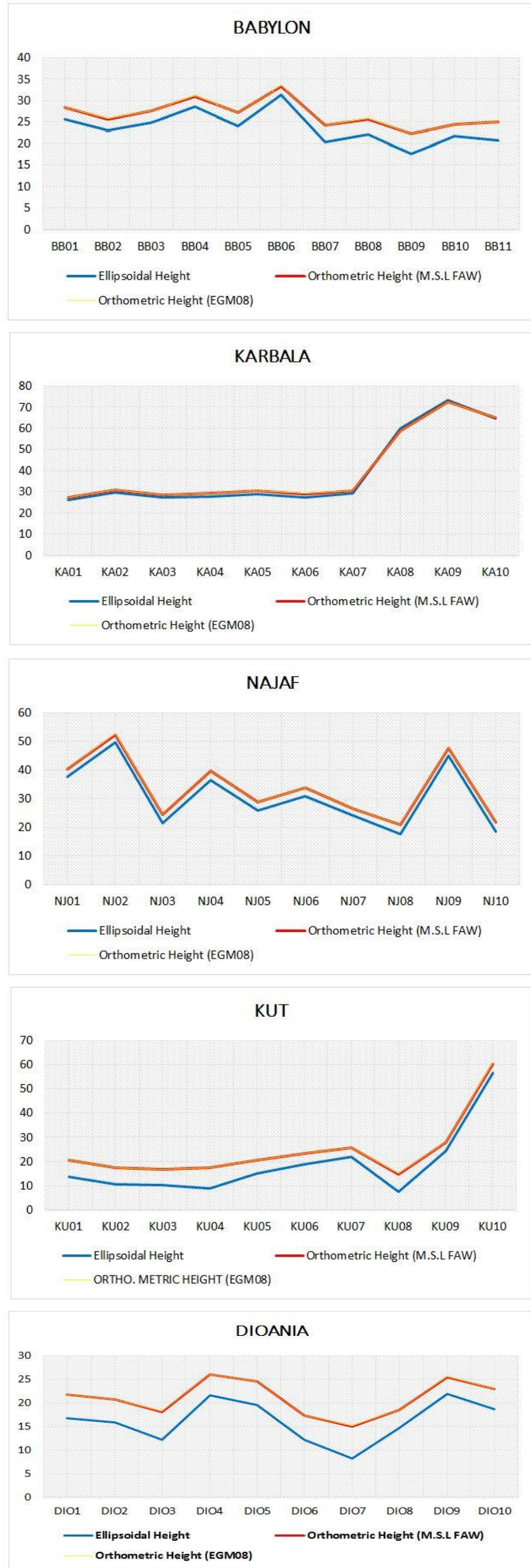

Fig. 12. The difference between orthometric height based on Faw M.S.L and EGM08 and ellipsoidal height 
The root mean square error (RMSE) has been calculated for each province based on Faw orthometric height and the orthometric height obtained from GNSSbased on EGM08. Table (1) shows the value of RMSE for each province. The highest value is in Kut province $(0.1361)$ and the lowest value is in Najaf province $(0.0283)$.

Table 1. The RMSE of Each Province.

\begin{tabular}{|c|c|c|}
\hline No. & Province & RMSE \\
\hline 1 & BABYLON & 0.0438 \\
\hline 2 & KARBALA & 0.0416 \\
\hline 3 & NAJAF & 0.0283 \\
\hline 4 & KUT & 0.1361 \\
\hline 5 & DIOANIA & 0.0600 \\
\hline
\end{tabular}

According to RMSE results, one must not rely on just EGM08 without considering the correction value of each province. Thus, in order to get accurate elevation, this correction has to be added.

Figure (13) illustrates the geoid undulation based on EGM08 and the adjusted one based on the observation related to Faw mean sea level in each province. In Babylon province, the adjustment value is ranging around $(-0.02 \mathrm{~m}$ to $-0.07 \mathrm{~m})$. In Karbala province, it is ranging ($0.05 \mathrm{~m}$ to $0.05 \mathrm{~m})$. In addition, the figure clears that the geoid undulation can be positive or negative which means the geoid can be higher than ellipsoid and vice versa. It is ranging from ( -0.05 to 0.01$)$ in Najaf province and from $(-0.08$ to -0.18$)$ in Kut province and from $(-0.01$ to -0.08$)$ in Dioania province.

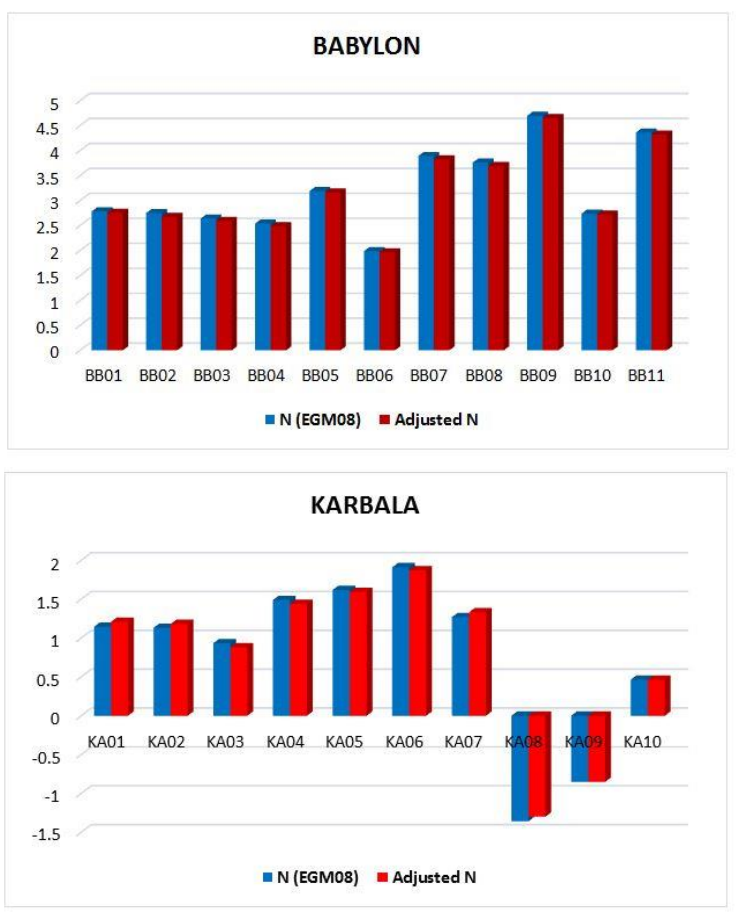

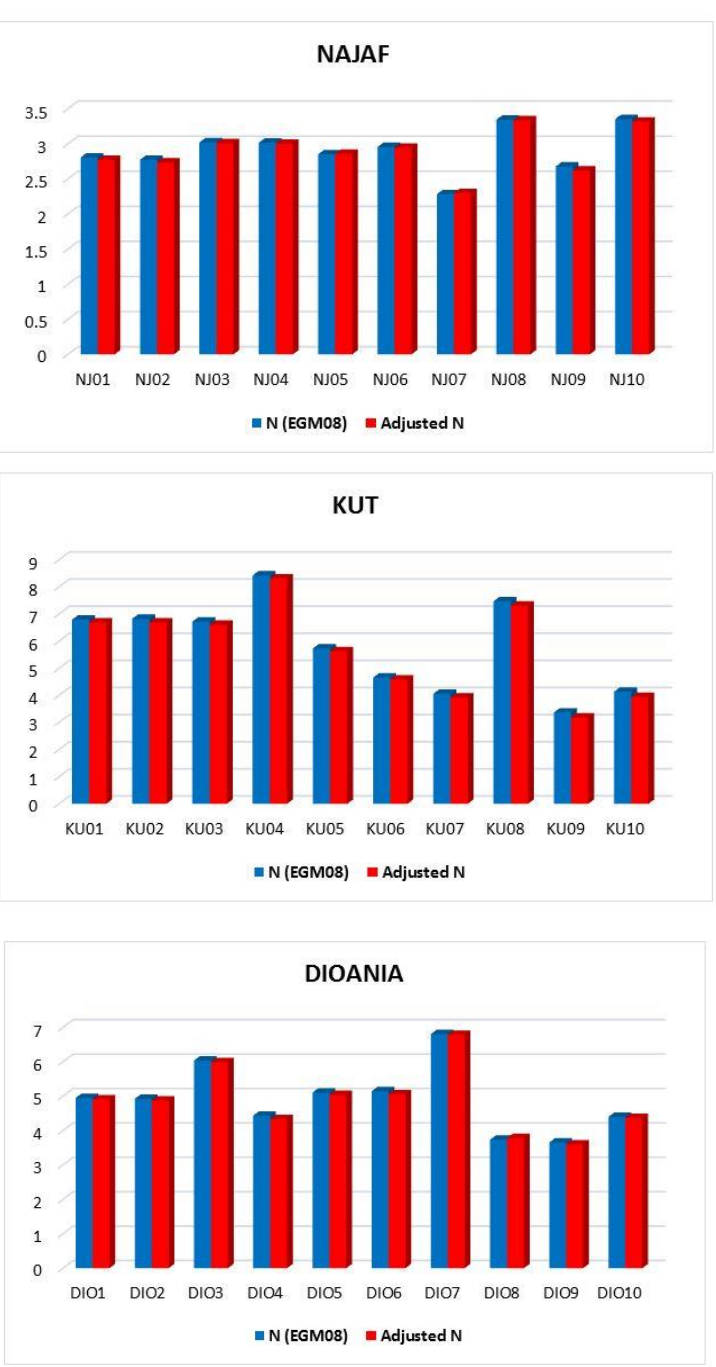

Fig. 13. Geoid undulation based on EGM08 and Faw M.S.L.

Table 2 clarifies the average adjustment value for each province that should be added to the geoid undulation $(\mathrm{N})$ obtained by GNSS technique based on EGM08. These values based on the observation of local vertical network and the HARN points that measured by GNSS technique and by precise level related to the nearest local vertical point (Faw M.S.L). As a result, EGM08 can be used as second order in Karbala and Najaf province and as third order in the Iraq middle provinces. In the northern provinces (Erbil, Duhok, and Sulimania), EGM08 cannot be used due to the high differences. 
Table 2. The Average Adjustment Value for each province.

\begin{tabular}{|c|c|}
\hline Province & Average ajustement value \\
\hline BAGHDAD & 0.058 \\
\hline BABYLON & -0.044 \\
\hline KARBALA & 0.007 \\
\hline NAJAF & -0.019 \\
\hline KUT & -0.134 \\
\hline DIOANIA & -0.045 \\
\hline MUTHANA & 0.110 \\
\hline THI QAR & 0.067 \\
\hline MISSAN & 0.149 \\
\hline BASRAH & 0.148 \\
\hline ERBIL & -0.293 \\
\hline DUHOK & 0.323 \\
\hline
\end{tabular}

\section{Conclusions}

Global Navigation Satellite System (GNSS) is considered as an advanced technique in the field of geodetic surveying due to the capability of this technique over the conventional techniques (theodolite, level, and total station) in terms the number of operators, time-saving, intervisibility, and accuracy. However, regarding the height, this technique measures the ellipsoidal height whereas the most significant height in all application is the orthometric height. To do this transformation (ellipsoid to orthometric height) a geoid model has to be used.

In Iraq there is no specific geoid that can be used to get proper orthometric height which supposed to be based on Faw mean sea level. In this research, EGM08 has been used to calculate the adjusted geoid undulation $(\mathrm{N})$ based on the difference in orthometric height related to Faw M.S.L and the one obtained based on EGM08. The result shows that EGM08 can be utilized as second order in Karbala and Najaf province and as third order in the other provinces.

The adjusted geoid undulation has been calculated in this research for different provinces in Iraq. The results of current research can improve the accuracy of the orthometric height or elevation obtained by GNSS technique and can support the establishing of Iraq geoid.

For future work, gravity observation can be combined with the height observation to improve the accuracy and establishing Iraq geoid. In addition, this research can be improved by increase the number of observations for local vertical network.

We acknowledge Mr. Wisam Abdulkadhim Hussein for his support our research.

\section{References}

1. P. Banerjee, G.R. Foulger, C.P. Dabral, JGEOD 73, 79 (1999)

2. C. Kotsakis, M.G. Sideris, JGEOD 73, 412 (1999)

3. T. Statella, S.M. Figueiredo, P. Pina, In EPSC, Proc. (2015) in Nantes, France, 10, 722
4. C. Conrad, "Lecture 3: Earth's figure, gravity, and geoid", GG612 Accelerated Introduction to Geology II, SOEST - University of Hawaii (2012)

5. C.A. Stein, Eos 72, 427 (1991)

6. A.M. Ali, ARJ 2, 403 (2016) 
Appendix 1. The coordinates of observed HARN points

\begin{tabular}{|c|c|c|}
\hline Point & Easting & Northing \\
\hline BB01 & 445659.061 & 3592819.7 \\
\hline BB02 & 443736.413 & 3584152.909 \\
\hline BB03 & 442835.171 & 3597549.892 \\
\hline BB04 & 443602.3 & 3613534.543 \\
\hline BB05 & 457277.38 & 3600852.993 \\
\hline BB06 & 431730.219 & 3621461.54 \\
\hline BB07 & 470106.774 & 3573983.26 \\
\hline BB08 & 469123.409 & 3584645.148 \\
\hline BB09 & 463508.833 & 3623595.085 \\
\hline BB10 & 492143.906 & 3576685.799 \\
\hline BB11 & 440229.46 & 3564725.332 \\
\hline
\end{tabular}

\begin{tabular}{|c|c|c|}
\hline Point & Easting & Northing \\
\hline KA01 & 409340.254 & 3607834.579 \\
\hline KA02 & 408815.477 & 3606646.723 \\
\hline KA03 & 404579.759 & 3612578.621 \\
\hline KA04 & 418611.68 & 3617593.267 \\
\hline KA05 & 421573.083 & 3615541.836 \\
\hline KA06 & 426359.612 & 3601107.469 \\
\hline KA07 & 411972.079 & 3603203.652 \\
\hline KA08 & 357514.788 & 3604916.925 \\
\hline KA09 & 366649.802 & 3592854.586 \\
\hline KA10 & 394084.669 & 3604209.325 \\
\hline
\end{tabular}

\begin{tabular}{|c|c|c|}
\hline Point & Easting & Northing \\
\hline NJ01 & 438934.689 & 3541957.799 \\
\hline NJ02 & 437908.366 & 3539101.114 \\
\hline NJ03 & 444290.981 & 3544422.876 \\
\hline NJ04 & 443725.27 & 3535673.783 \\
\hline NJ05 & 441521.232 & 3556020.418 \\
\hline NJ06 & 442447.529 & 3540267.75 \\
\hline NJ07 & 431669.35 & 3576034.106 \\
\hline NJ08 & 452933.579 & 3517705.85 \\
\hline NJ09 & 435985.496 & 3543556.703 \\
\hline NJ10 & 452022.621 & 3529910.13 \\
\hline
\end{tabular}

